\title{
Apolipoprotein E synthesized by adipocyte and apolipoprotein E carried on lipoproteins modulate adipocyte triglyceride content
}

Yan-hong Li and Ling Liu*

\begin{abstract}
Excessive energy storage of adipose tissue makes contribution to the occurrence and progression of obesity, which accompanies with multiple adverse complications, such as metabolic syndrome, cardiovascular diseases. It is well known that apolipoprotein $\mathrm{E}$, as a component of lipoproteins, performs a key role in maintaining plasma lipoproteins homeostasis. Interestingly, apolipoprotein $\mathrm{E}$ is highly expressed in adipocyte and has positive relation with body fat mass. Apolipoprotein E knock-out mice show small fat mass compared to wild type mice. Moreover, adipocyte deficiency in apolipoprotein E shows impaired lipoproeteins internalization and triglyceride accumulation. Apolipopreotein E-deficient lipoproteins can not induce preadipocyte to form round full-lipid adipocyte, whereas apolipoprotein E-containing lipoproteins can. This article mainly reviews the modulation of apolipoprotein E synthesized by adipocyte and apolipoprotein E carried on lipoproteins in adipocyte triglyceride content.
\end{abstract}

Keywords: Apolipoprotein E, Adipocyte, Triglyceride, Receptor-mediated endocytosis

\section{Introduction}

During recent decades, obesity has reached epidemic proportions globally in developed and developing countries [1]. A person, with body mass index $\geq 30 \mathrm{~kg} / \mathrm{m}^{2}$ or waist-hip ratio $\geq 102 \mathrm{~cm}$ for men and $\geq 88$ for women, is defined as obesity according to the World Health Organization [2]. What is becoming increasingly evident is that obesity has become an independent risk of lifethreatening diseases, such as insulin resistance, diabetes, cardiovascular diseases, stroke and certain cancers [3-6]. Those diseases have high morbidity and mortality, laying a huge economic burden on the society and the patient family. In addition, with the change of social acceptance and socio-cultural factors, overweight and obese individuals might suffer from psychological distress, for example, self-depreciation and depression [7]. Physical and psychological disorders induced by obesity have become increasingly serious public health problems. Therefore, it is worthy to better understand adipocyte and adipose tissue physiology.

\footnotetext{
* Correspondence: feliuling@medmail.com.cn

Department of Cardiology, the Second Xiangya Hospital, Central South University, \#139 Middle Renmin Road, Changsha, Hunan 410011, PR China
}

Obesity is characterized with excessive adipose tissue mass. Adipose tissue can greatly expand its energy-buffering capacity by adipocyte hypertrophy and/or by adipocyte hyperplasia [8]. Adipocyte hypertrophy is defined as expanding in adipocyte size resulting from uptake fatty acids (FFA) and storage in form of triglyceride (TG). Adipocyte hyperplasia, also named adipogenesis, is termed as increase in adipocyte number, resulting from proliferation of undifferentiated fibroblast-like adipocyte progenitors and then differentiation into mature round lipid-filled adipocyte [9]. Adipocyte hypertrophy often precedes adipocyte hyperplasia in humans and animals [9].

Apolipoprotein E (ApoE), molecular mass of $34.5 \mathrm{kDa}$, is a glycoprotein coded by 299 amino acids. Due to amino acids rich in arginine, ApoE is also named as "argininerich" apolipoprotein [10], which is synthesized mainly by liver [11]. Other tissues and cells, like brain, kidney, adipocyte, smooth muscle cells and macrophages, also can produce ApoE [12,13]. As a component of lipoproteins, ApoE mediates lipoproteins internalization and degradation via receptor-mediated endocytosis pathways. Recently, numerous studies have demonstrated that strong positive correlations exist between ApoE and triglyceride accumulation in adipocyte. ApoE synthesized by adipocyte is 
associated with adipocyte hypertrophy in vivo and in vitro [14-16]. ApoE carried on circulating lipoproteins is essential in lipoproteins-induced adipogenesis [17]. ApoE has three isoforms in humans, however, the relationship between ApoE polymorphism and body fat mass is still controversial [18-20].

\section{Apolipoprotein E}

ApoE is a major component of very low density lipoproteins (VLDL), remnant lipoproteins (RLPs) and high density lipoproteins (HDL). In the early 1970s, ApoE was firstly discovered as a protein component of VLDL [21]. VLDL from live and chylomicron from intestine are termed as triglyceride-rich lipoproteins (TRLs). TRLs become enriched in ApoE as they are lipolyzed on the surface of endothelial cells by lipoprotein lipase (LPL) and convert into RLPs [22,23]. Moreover, ApoE recycles among lipoproteins particles. TRLs with the higher content in ApoE provide material for ApoE and particle recycling. Once internalized, the majority of TRLs-derived ApoE remains in early endosomes. Upon stimulation with HDL or HDL-derived apolipoprotein A-I, ApoE can be recycled back to the plasma membrane, followed by ApoE re-secretion and the subsequent formation of ApoE-containing HDL. The HDL-induced recycling of ApoE may drive cholesterol efflux or capture new remnants $[24,25]$.

ApoE on the surface of lipoproteins is served as a natural ligand of receptors, which is essential in the metabolism of lipoproteins. Associated receptors includes low density lipoproteins receptor (LDLr), LDL receptorrelated protein (LRP), VLDL receptor (VLDLr), heparin sulfate proteoglycans (HSPGs) [22,26,27]. These receptors are also termed as ApoE-recognizing receptors. LDLr, VLDLr and LRP belong to LDL receptor family, which bind ApoE in clathrin-dependent pathway [26] and preferentially clear a subset of large TRLs particles enriched in ApoE [28]. However, as specific HSPGs, syndecan-1 mediates lipoproteins endocytosis in lipid raft-dependent fashion [29] and preferentially clear small particles enriched in ApoE and apolipoprotein AV [28]. In addition, ApoEcontaining HDL participate in cholesterol efflux and contribute to the maintenance of plasma and tissue cholesterol homeostasis [22,23,30].

Interestingly, ApoE is polymorphic and its function shows isoforms specificity in humans. There are three alleles, $\varepsilon 2, \varepsilon 3$ and $\varepsilon 4$, and encoding there isforms ApoE2, ApoE3 and ApoE4, respectively [31]. The ApoE3 isoform is the most common genotype, accounting for about $78 \%$. Recently, the rare haplotype has been reported in several subjects. This fourth ApoE allele is similar to $\varepsilon 3$, and termed as the $\varepsilon 3 \mathrm{r}$ allele that encodes the ApoE3r isoform [31,32]. In the lipid-binding function, ApoE3 and ApoE2 preferentially bind the smaller, highly curved lipid emulsions (e.g., HDL), while ApoE4 prefers larger, less curved lipid emulsions (i.e., VLDL). ApoE2 is weaker than ApoE3 and ApoE4 in the receptor-binding capacity. However, the heparin-binding function do not seem to be any major difference among there isoforms [22].

Clinically, the ApoE2 carriers have elevated plasma TG level and are prone to developing type III dyslipoproteinemia, which increase the risk for metabolic-associated diseases [33,34]. The ApoE4 carriers have higher risk for cardiovascular disease, which attributed to higher concentrations of LDL-cholesterol [35]. Emerging studies showed that the impact of ApoE2 and ApoE4 on the cardiovascular disease risk phenotype was influenced by lipid fractions, inflammatory profile and adiposity in humans $[36,37]$. Due to the very rarity of the ApoE3r isoform, its effect on lipoproteins metabolism remains unknown, and requires further investigations.

\section{The relationship between ApoE and body fat mass}

It is well known that LPL is the rate-limiting enzyme for the hydrolysis of TG in core of TRLs and deficiency of this enzyme induces severe hypertriglyceridemia in humans and mice $[38,39]$. Adipose fat storage is thought to require uptake of circulating TG-derived fatty acids mediated by LPL. However, humans with LPL deficiency and adipose-specific LPL deficient mice showed normal body fat mass [40,41]. Recent report showed that hypertriglyceridaemia induced by the loss of LpL was associated with reduced TG uptake into brown adipose tissue, but white adipose tissue fat accumulation was normal [42]. In adipose tissue of LPL deficiency, chemical composition revealed that lipid storage maintained mainly by enhanced endogenous adipocte fatty acid synthesis $[39,41]$. Increased de novo adipocyte lipogenesis could compensate for adipose LPL deficiency and play an important role in body fat mass. Therefore, it could conjecture that LPL-independent pathways contribute to adipocyte TG storage.

One possible LPL-independent pathway is receptormediated endocytosis in obesity. It was demonstrated that Apolipoprotein C-I specifically inhibited VLDL binding LDL receptor family [43]. Interestingly, human apolipoprotein C-I transgenic mice were protected from obesity [44]. Moreover, mice knocking out VLDLr or LRP displayed lower body weight compared with wild type (WT) controls [45,46]. VLDLr-deficient patients were also underweight, with body mass index less than 18.5 [47]. ApoE is one of important ligands for these receptors binding lipoproteins. It seems reasonable to speculate that the receptormediated pathways associated with ApoE could perform a potential role in body fat mass.

The crucial role of ApoE in body fat mass has been clearly demonstrated in ApoE knock-out (EKO) mice. EKO mice feeding on a chow diet or high-fat diet were more resistant to the development of obesity than WT 
controls. Deletion of ApoE in genetic mutation obese mice, such as leptin deficient mice and $\mathrm{Ay}^{/+}$mice, also prevented diet-induced obesity by either a high-cholesterol diet or high-sucrose diabetogenic diet $[17,48,49]$. EKO adipocyte showed low-level TG, low FFA content and limited lipoproteins uptake than WT controls [14-16]. However, the levels of TG and FFA doubled in cultured EKO adipocyte overexpressing adenoviral-mediated ApoE3 [14].

In humans, there is no established link between the loss of ApoE and body fat mass due to extremely rare ApoE-deficiency condition. It is well known ApoE is essential in the catabolism of lipoprorteins. Although EKO mice could prevent diet-induced obesity, it spontaneously develops severe hypercholesterolemia and atherosclerotic lesions that are similar to those found in humans [50,51]. EKO mice is the most ideal genetically modified animal in atherosclerosis research. Therefore, the lack of functional ApoE have severe metabolic disorders, and the extremely rare ApoE-deficiency condition may be in accordance with the favourable selective pressure in humans.

However, it is also controversial about the relationship between ApoE polymorphism and obesity in different race. According to population epidemiological statistics, the ApoE3 isoform is the most common genotype and considered as wild type. A study showed that ApoE2 was a strong indicator for human obesity in the Roma and Turkish subjects $[18,52]$. However, the Tehran Lipid and Glucose Study did not show any relation between ApoE isoforms and obesity in a Tehranian population [19]. ApoE genotype in obese population showed no significant statistical difference compared with that of lean controls in Chinese population of Chengdu area [20]. Actually, it is hard to definitely evaluate ApoE polymorphism in obesity on account of almost unavailable ApoE2 and ApoE4 homozygous in humans.

Interestingly, the effect of ApoE polymorphism in body fat mass existed significant difference in mice. ApoE2 knock-in mice were to easily develop hepertriglycerdemia and diet-induced obesity [53,54]. However, ApoE4 knock-in mice presented a lower body mass index and reduction of adipogenesis after feeding highfat Western-type diet [55]. The difference between mice and humans could be explained by different constituent and metabolism of lipoproteins. About 70\% VLDL from mice contain apolipoprotein B48 particles, whereas all VLDL from humans contain apolipoprotein B100 particles [54]. Apolipoprotein B48 is a truncated form of apolipoprotein $\mathrm{B}$, which does not contain the carboxylterminal portion of apo B and can not bind to LDL receptors. However, apolipoprotein B100 can be recognized by LDL receptor. Thus, mice depend more on apoE for VLDL clearance than humans do. Therefore, results from ApoE transgenic mice cannot be extrapolated to humans without taking this significant difference into consideration.

\section{ApoE synthesized by adipocyte in adipocyte triglyceride accumulation}

More than two decades ago, Zechner et al. [13] firstly observed that adipocyte expressed high abundance of ApoE. Interestingly, adipocyte-derived ApoE expression was exactly paralleled with the development of visible lipid droplets in a differentiation-dependent fashion in vitro $[13,56]$. It has been widely established that peroxisome proliferator-activated receptor gramme (PPAR $\gamma$ ) is an essential regulator of adipogenesis [57]. More interestingly, PPAR $\gamma$ agonists increased the expression of adipocyte ApoE in vitro and in vivo [58]. Addition PPARy agonists (i.e.rosiglitazone) to WT adipocyte led to TG and FFA accumulation, accompanying with a fourfold increase in adipocyte ApoE expression. However, those effects were blunted in EKO mice [14]. It could indicate that ApoE synthesized by adipocyte may have relation with adipocyte triglyceride accumulation.

ApoE synthesized by adipocyte performed an indispensable role in adipocyte triglyceride accumulation. In order to discriminate the potential effects of various derived ApoE in adipocyte triglyceride accumulation, Huang et al. [15] transplanted epididymal white adipose tissue from EKO or age- and gender-matched WT donors into WT recipients, respectively, to form EKO-WT and WT-WT models in vivo. After feeding either chow diet or high-fat diet for $8 \sim 10$ weeks, transplanted white adipose tissue was harvested. EKO-WT adipocyte displayed smaller size, lower TG content, higher TG hydrolysis and lower TG synthesis than WT-WT controls. This difference was not because of absence of ApoE carried on circulating lipoproteins but ApoE derived from adipocyte. Thus, ApoE carried on lipoproteins could not correct the deficiency in triglyceride accumulation of EKO adipocyte.

There were two possible mechanisms to explain the impaired lipid storage in EKO adipocyte. On one hand, caveolin-1 (cav-1) were significantly suppressed in EKO adipocyte, which led to the impairment of both transportation of FFA across the adipocyte membrane and subsequent adipocyte triglyceride synthesis $[14,16,48,59]$. This defect could be corrected by increasing cav-1 expression using viral transduction in cultured EKO adipocytes [16]. Cav-1 was a major functional protein of caveolae that were specialized membrane invaginations accounting for a third of adipocyte plasma membrane [60,61]. During adipogenesis of 3 T3-L1 cells, a widely used model system for studying adipogenesis, cav-1 was dramatically induced as compared with the undifferentiated fibroblastic state [60]. Cav-1 null mice were overtly resistant to dietinduced obesity, lying in an inability to lipid storage in adipocyte [62]. Interestingly, adipocyte ApoE was colocalized 
with cav-1 at the adipocyte plasma membrane [63]. However, more detailed functional data will be needed to further elucidate the interaction between adipocyte ApoE and cav-1 in cellular lipid storage.

On the other hand, EKO adipocyte showed impaired receptor-mediated endocytosis. The expressions of ApoErecognizing receptors were reduced in EKO adipocyte, or these receptors, such as VLDLr and LRP, redistributed away from the cell membrane surface [16]. It have reported that VLDLr were strongly induced during $3 \mathrm{~T} 3-\mathrm{L} 1$ adipogenesis [64]. Moreover, VLDLr deficiency protected mice from obesity [45]. The consistent results were observed in VLDLr-deficient subjects in humans. VLDLrdeficient patients had abnormally low body mass index (less than 18.5) compared with control subjects [47]. The increased expression of LRP was associated with proportionally increased endocytic activity in 3 T3-L1 adipocyte [65]. And mice with adipocyte-specific deletion LRP displayed smaller body fat than WT controls [46]. Thus, receptor-mediated endocytosis could promote adipocyte TG accumulation.

\section{ApoE carried on lipoproteins in adipocyte triglyceride accumulation}

Circulation fatty acids that are available for adipocyte uptake are either hydrolysis product from TRLs by LPL, or in the form of TRLs. TRLs provides a concentrated source of esterified fatty acids, which could be directly internalized by adipocyte endocytic receptors, for example VLDLr, LRP, LDLr $[16,45,46]$. These receptors transport internalized lipoproteins to lysosomes for degradation, and producing intracellular FFA is assimilated into TG-rich storage droplets. It has been well clarified that these endocytic receptors via recognizing ApoE perform a vital role in hepatic clearance of TRLs and their remnant [28]. However, it deserves to explore whether or not ApoE takes part in receptor-mediated endocytic pathways in adipocyte triglyceride accumulation.

Tsuyoshi Chiba et al. [17] firstly demonstrated that ApoE carried on lipoproteins was essential for VLDL-induced adipogenesis. VLDL from WT mice induced the differentiation of bone marrow stromal cells to mature adipocyte with large lipid droplets, whereas ApoE-deficient VLDL from EKO mice failed. Similarly, selective removal of ApoE from human VLDL via trypsin treatment impaired the adipogenic effect of human VLDL. And preincubation of ApoE-deficient VLDL with recombinant human ApoE partially recovered the adipogenic activity.

The most possible mechanism of VLDL-induced adipogenesis was that adipocyte internalized VLDL particles via ApoE receptors [17]. This viewpoint is consistent with a previous study that ApoE at the surface of lipoproteins was required in receptor-mediated endocytosis in mice and humans [66]. EKO mice were more resistant to gaining body fat than LDLr deficiency mice, suggesting ApoE-dependent receptors, for example LRP, VLDLr, HSPG, could take part in adipocyte triglyceride accumulation [23]. However, it remains to be clarified which receptor has a stronger influence on adipocyte triglyceride accumulation.

HSPGs were independent of LDLr family members in clearance of both intestinally derived and hepatic lipoprotein particles [67]. It also showed that HSPGs increased in differentiated adipocyte and contributed to adipocyte triglyceride accumulation [68]. ApoE2 carriers have elevated TG level due to impaired hepatic clearance of TRLs. Interestingly, ApoE2 konck-in mice could promote diet-induced obesity [53]. Although ApoE2 is defective in binding to LDLr, it could bind to HSPGs that can directly take up lipoproteins [69]. Moreover, HSPGs could play an important role in clearing TRLs and RLPs in animal postprandial condition (e.g. acute lipid loading state) [28]. It could conjecture that HSPG would be a major contributor to internalization lipoproteins, which lead to distribution of dietary fat from circulation to adipocytes.

Since the essential role of ApoE carried on lipoproteins in adipogenensis, it is reasonable to speculate that the effect of RLPs in adipogenesis could be stronger than that of VLDL. RLPs are smaller lipolytic products of TRLs. Compared with nascent TRLs, RLPs are with a higher density and more ApoE and cholesteryl ester. Clinical studies showed that plasma RLP-cholesterol concentrations obviously elevated in the postprandial state of obese individuals [70,71]. RLPs could induce adipogenic differentiation of adipose mesenchymal stem cells in human and rat $[72,73]$. Due to more ApoE in RLPs than VLDL, the ability of RLPs-induced adipogenesis could be stronger than that of VLDL.

It is important to mention how circulating lipoproteins traverse endothelium and become accessible to adipocyte and proadipocyte in vivo? It is well known that the endothelium forms a negatively charged barrier preventing the leakage of charged (macro) molecules (i.e., circulating lipoproteins) into the arterial wall. However, endothelial injury and increased lipoprotein accumulation in the artery wall have been viewed as an early event in development of atherosclerosis. LDL and TRLs are deleterious to the endothelium and can increase permeability of endothelial cell. Thus, these atherogenic lipoproteins can cross the the endothelial layer into the subendothelial space and are detectable as part of foam cells in vascular lesion [74-77]. Lipolysis products by LPL located on the capillary endothelial surface also have direct endothelial toxicity and increase the lipoproteins permeability across endothelial monolayers $[76,78]$. Moreover, adipocyte progenitors cell resided in the mural cell compartment of the adipose vasculature. Adipose vasculature, as a proadipocyte niche, might provide signal for adipogenesis [79]. Above analysis could explain 
the potential mechanisms of increase access of lipoproteins to adipocyte and proadipocyte. However, more detailed information needs further investigation.

\section{Conclusion}

It is elaborated that deficiency of ApoE is more resistant to obesity in mice. ApoE synthesized by adipocyte plays an indispensable role in adipocyte triglyceride accumulation. ApoE carried on VLDL is essential for VLDL-induced adipogenesis. It seems that ApoE from a variety of resources performs an equally vital role in adipocyte triglyceride accumulation, although the more detailed mechanisms need further study.

\section{Abbreviations \\ FFA: Free fatty acid; TG: Triglyceride; ApoE: Apolipoprotein E; VLDL: Very low-density lipoprotein; RLPs: Remnant lipoproteins; HDL: High-density lipoprotein; TRLs: Triglyceride-rich lipoproteins; LPL: Lipoprotein lipase; LDLr: Low-density lipoprotein receptor; LRP: LDL receptor-related protein; VLDLr: Very low-density lipoprotein receptor; HSPGs: Heparin sulfate proteoglycans; WT: C57BL/6 wild type; EKO: ApoE knock-out; PPARY: Peroxisome Proliferator-activated receptor gramme; cav-1: Caveolin-1.}

\section{Competing interest}

The authors declare that they have no competing interests.

\section{Authors' contributions}

$Y L$ conceived of lay out and wrote the paper. $L L$ helped to draft the manuscript and gave final approval of the version to be published. Both authors read and approved the final manuscript.

\section{Acknowledgments}

This study was supported by the National Natural Science Foundation of China (81270956), Hunan Provincial Natural Science Foundation of China (10JJ1008 and 11JJ7005), Program for Changjiang Scholars and Innovative Research Team in University (IRT1195).

Received: 18 May 2014 Accepted: 18 August 2014

Published: 23 August 2014

\section{References}

1. Berghofer A, Pischon T, Reinhold T, Apovian CM, Sharma AM, Willich SN: Obesity prevalence from a European perspective: a systematic review. BMC Public Health 2008, 8:200.

2. Obesity: preventing and managing the global epidemic. Report of a WHO consultation. World Health Organ Tech Rep Ser 2000, 894:1-253. i-xii.

3. Shoelson SE, Herrero L, Naaz A: Obesity, inflammation, and insulin resistance. Gastroenterology 2007, 132(6):2169-2180.

4. Rega-Kaun G, Kaun C, Wojta J: More than a simple storage organ: adipose tissue as a source of adipokines involved in cardiovascular disease. Thromb Haemost 2013, 110(4):641-650.

5. Kurth T, Gaziano JM, Berger K, Kase CS, Rexrode KM, Cook NR, Buring JE, Manson JE: Body mass index and the risk of stroke in men. Arch Intern Med 2002, 162(22):2557-2562.

6. Calle EE, Rodriguez C, Walker-Thurmond K, Thun MJ: Overweight, obesity, and mortality from cancer in a prospectively studied cohort of U.S. adults. N Engl J Med 2003, 348(17):1625-1638.

7. Atlantis $E$, Ball K: Association between weight perception and psychological distress. Int J Obes (Lond) 2008, 32(4):715-721.

8. Unger RH, Scherer PE: Gluttony, sloth and the metabolic syndrome: a roadmap to lipotoxicity. Trends Endocrinol Metab 2010, 21(6):345-352.

9. Hausman DB, DiGirolamo M, Bartness TJ, Hausman GJ, Martin RJ: The biology of white adipocyte proliferation. Obes Rev 2001, 2(4):239-254.

10. McLean JW, Elshourbagy NA, Chang DJ, Mahley RW, Taylor JM: Human apolipoprotein E mRNA. cDNA cloning and nucleotide sequencing of a new variant. J Biol Chem 1984, 259(10):6498-6504.
11. Kraft HG, Menzel HJ, Hoppichler F, Vogel W, Utermann G: Changes of genetic apolipoprotein phenotypes caused by liver transplantation. Implications for apolipoprotein synthesis. J Clin Invest 1989, 83(1):137-142.

12. Driscoll DM, Getz GS: Extrahepatic synthesis of apolipoprotein E. J Lipid Res 1984, 25(12):1368-1379.

13. Zechner R, Moser R, Newman TC, Fried SK, Breslow JL: Apolipoprotein E gene expression in mouse 3 T3-L1 adipocytes and human adipose tissue and its regulation by differentiation and lipid content. J Biol Chem 1991, 266(16):10583-10588.

14. Huang ZH, Reardon CA, Mazzone T: Endogenous ApoE expression modulates adipocyte triglyceride content and turnover. Diabetes 2006, 55(12):3394-3402.

15. Huang ZH, Gu D, Mazzone T: Role of adipocyte-derived apoE in modulating adipocyte size, lipid metabolism, and gene expression in vivo. Am J Physiol Endocrinol Metab 2009, 296(5):E1110-E1119.

16. Huang ZH, Minshall RD, Mazzone T: Mechanism for endogenously expressed ApoE modulation of adipocyte very low density lipoprotein metabolism: role in endocytic and lipase-mediated metabolic pathways. J Biol Chem 2009, 284(46):31512-31522.

17. Chiba T, Nakazawa T, Yui K, Kaneko E, Shimokado K: VLDL induces adipocyte differentiation in ApoE-dependent manner. Arterioscler Thromb Vasc Biol 2003, 23(8):1423-1429.

18. Zeljko HM, Skaric-Juric T, Narancic NS, Tomas Z, Baresic A, Salihovic MP, Starcevic B, Janicijevic B: E2 allele of the apolipoprotein E gene polymorphism is predictive for obesity status in Roma minority population of Croatia. Lipids Health Dis 2011, 10:9.

19. Zarkesh M, Daneshpour MS, Faam B, Hedayati M, Azizi F: Is there any association of apolipoprotein $\mathrm{E}$ gene polymorphism with obesity status and lipid profiles? Tehran Lipid and Glucose Study (TLGS). Gene 2012, 509(2):282-285.

20. Zhang J, Xuemei Z, Fan P, Liu R, Huang Y, Liang S, Liu Y, Wu Y, Bai H: Distribution and effect of apo $E$ genotype on plasma lipid and apolipoprotein profiles in overweight/obese and nonobese Chinese subjects. J Clin Lab Anal 2012, 26(3):200-205.

21. Shore VG, Shore B: Heterogeneity of human plasma very low density lipoproteins. Separation of species differing in protein components. Biochemistry 1973, 12(3):502-507.

22. Mahley RW, Rall SC Jr: Apolipoprotein E: far more than a lipid transport protein. Annu Rev Genomics Hum Genet 2000, 1:507-537.

23. Kypreos KE, Karagiannides I, Fotiadou EH, Karavia EA, Brinkmeier MS, Giakoumi SM, Tsompanidi EM: Mechanisms of obesity and related pathologies: role of apolipoprotein $\mathrm{E}$ in the development of obesity. FEBS J 2009, 276(20):5720-5728.

24. Heeren J, Beisiegel U, Grewal T: Apolipoprotein E recycling: implications for dyslipidemia and atherosclerosis. Arterioscler Thromb Vasc Biol 2006, 26(3):442-448.

25. Laatsch A, Panteli M, Sornsakrin M, Hoffzimmer B, Grewal T, Heeren J: Low density lipoprotein receptor-related protein 1 dependent endosomal trapping and recycling of apolipoprotein E. PLoS One 2012, 7(1):e29385.

26. Strickland DK, Gonias SL, Argraves WS: Diverse roles for the LDL receptor family. Trends Endocrinol Metab 2002, 13(2):66-74.

27. Gonzales JC, Gordts PL, Foley EM, Esko JD: Apolipoproteins E and AV mediate lipoprotein clearance by hepatic proteoglycans. J Clin Invest 2013, 123(6):2742-2751.

28. Foley EM, Gordts PL, Stanford KI, Gonzales JC, Lawrence R, Stoddard N, Esko JD: Hepatic remnant lipoprotein clearance by heparan sulfate proteoglycans and low-density lipoprotein receptors depend on dietary conditions in mice. Arterioscler Thromb Vasc Biol 2013, 33(9):2065-2074.

29. Chen K, Williams KJ: Molecular mediators for raft-dependent endocytosis of syndecan-1, a highly conserved, multifunctional receptor. $J$ Biol Chem 2013, 288(20):13988-13999.

30. Vasquez EC, Peotta VA, Gava AL, Pereira TM, Meyrelles SS: Cardiac and vascular phenotypes in the apolipoprotein E-deficient mouse. J Biomed Sci 2012, 19:22.

31. Seripa D, Matera MG, Daniele A, Bizzarro A, Rinaldi M, Gravina C, Bisceglia L, Corbo RM, Panza F, Solfrizzi V, Fazio VM, Forno GD, Masullo C, Dallapiccola B, Pilotto A: The missing ApoE allele. Ann Hum Genet 2007, 71(Pt 4):496-500.

32. Seripa D, D'Onofrio G, Panza F, Cascavilla L, Masullo C, Pilotto A: The genetics of the human APOE polymorphism. Rejuvenation Res 2011, 14(5):491-500.

33. Smelt AH: From gene to disease; apolipoprotein E2 and familial dysbetalipoproteinemia. Ned Tijdschr Geneeskd 2003, 147(4):157-159. 
34. Eto M, Saito M: Familial type III hyperlipoproteinemia. Nihon Rinsho 2013, 71(9):1590-1594

35. Bennet AM, Di Angelantonio E, Ye Z, Wensley F, Dahlin A, Ahlbom A, Keavney B, Collins R, Wiman B, de Faire U, Danesh J: Association of apolipoprotein $\mathrm{E}$ genotypes with lipid levels and coronary risk. JAMA 2007, 298(11):1300-1311.

36. Gungor Z, Anuurad E, Enkhmaa B, Zhang W, Kim K, Berglund L: Apo E4 and lipoprotein-associated phospholipase A2 synergistically increase cardiovascular risk. Atherosclerosis 2012, 223(1):230-234.

37. Kofler BM, Miles EA, Curtis P, Armah CK, Tricon S, Grew J, Napper FL, Farrell L, Lietz G, Packard CJ, Caslake MJ, Mathers JC, Williams CM, Calder PC, Minihane AM: Apolipoprotein E genotype and the cardiovascular disease risk phenotype: impact of sex and adiposity (the FINGEN study). Atherosclerosis 2012, 221(2):467-470.

38. Weinstock PH, Bisgaier CL, Aalto-Setala K, Radner H, Ramakrishnan R, LevakFrank S, Essenburg AD, Zechner R, Breslow JL: Severe hypertriglyceridemia, reduced high density lipoprotein, and neonatal death in lipoprotein lipase knockout mice. Mild hypertriglyceridemia with impaired very low density lipoprotein clearance in heterozygotes. J Clin Invest 1995, 96(6):2555-2568

39. Ullrich NF, Purnell JQ, Brunzell JD: Adipose tissue fatty acid composition in humans with lipoprotein lipase deficiency. J Investig Med 2001, 49(3):273-275.

40. Brun LD, Gagne C, Julien P, Tremblay A, Moorjani S, Bouchard C, Lupien PJ: Familial lipoprotein lipase-activity deficiency: study of total body fatness and subcutaneous fat tissue distribution. Metabolism 1989, 38(10):1005-1009.

41. Weinstock PH, Levak-Frank S, Hudgins LC, Radner H, Friedman JM, Zechner $R$, Breslow JL: Lipoprotein lipase controls fatty acid entry into adipose tissue, but fat mass is preserved by endogenous synthesis in mice deficient in adipose tissue lipoprotein lipase. Proc Natl Acad Sci U S A 1997, 94(19):10261-10266.

42. Garcia-Arcos I, Hiyama Y, Drosatos K, Bharadwaj KG, Hu Y, Son NH, O'Byrne SM, Chang CL, Deckelbaum RJ, Takahashi M, Westerterp M, Obunike JC, Jiang $H$, Yagyu $H$, Blaner WS, Goldberg IJ: Adipose-specific lipoprotein lipase deficiency more profoundly affects brown than white fat biology. J Biol Chem 2013, 288(20):14046-14058.

43. Shachter NS: Apolipoproteins C-I and C-III as important modulators of lipoprotein metabolism. Curr Opin Lipidol 2001, 12(3):297-304.

44. Jong MC, Voshol PJ, Muurling M, Dahlmans VE, Romijn JA, Pijl H, Havekes LM: Protection from obesity and insulin resistance in mice overexpressing human apolipoprotein C1. Diabetes 2001, 50(12):2779-2785.

45. Goudriaan JR, Tacken PJ, Dahlmans VE, Gijbels MJ, van Dijk KW, Havekes LM, Jong MC: Protection from obesity in mice lacking the VLDL receptor. Arterioscler Thromb Vasc Biol 2001, 21(9):1488-1493.

46. Hofmann SM, Zhou L, Perez-Tilve D, Greer T, Grant E, Wancata L, Thomas A, Pfluger PT, Basford JE, Gilham D, Herz J, Tschöp MH, Hui DY: Adipocyte LDL receptor-related protein-1 expression modulates postprandial lipid transport and glucose homeostasis in mice. J Clin Invest 2007 117(11):3271-3282.

47. Boycott KM, Flavelle S, Bureau A, Glass HC, Fujiwara TM, Wirrell E, Davey K, Chudley AE, Scott JN, McLeod DR, Parboosingh JS: Homozygous deletion of the very low density lipoprotein receptor gene causes autosomal recessive cerebellar hypoplasia with cerebral gyral simplification. Am J Hum Genet 2005, 77(3):477-483.

48. Gao J, Katagiri H, Ishigaki Y, Yamada T, Ogihara T, Imai J, Uno K, Hasegawa Y, Kanzaki M, Yamamoto TT, Ishibashi S, Oka Y: Involvement of apolipoprotein $\mathrm{E}$ in excess fat accumulation and insulin resistance. Diabetes 2007, 56(1):24-33.

49. Hofmann SM, Perez-Tilve D, Greer TM, Coburn BA, Grant E, Basford JE, Tschop MH, Hui DY: Defective lipid delivery modulates glucose tolerance and metabolic response to diet in apolipoprotein E-deficient mice. Diabetes 2008, 57(1):5-12.

50. Ewart MA, Kennedy S, Macmillan D, Raja AL, Watt IM, Currie S: Altered vascular smooth muscle function in the ApoE knockout mouse during the progression of atherosclerosis. Atherosclerosis 2014, 234(1):154-161.

51. Vasquez EC, Peotta VA, Meyrelles SS: Cardiovascular autonomic imbalance and baroreflex dysfunction in the apolipoprotein E-deficient mouse. Cell Physiol Biochem 2012, 29(5-6):635-646.
52. Duman BS, Ozturk M, Yilmazer S, Hatemi H: Apolipoprotein E polymorphism in Turkish subjects with Type 2 diabetes mellitus: allele frequency and relation to serum lipid concentrations. Diabetes Nutr Metab 2004, 17(5):267-274.

53. Kuhel DG, Konaniah ES, Basford JE, McVey C, Goodin CT, Chatterjee TK, Weintraub NL, Hui DY: Apolipoprotein E2 accentuates postprandial inflammation and diet-induced obesity to promote hyperinsulinemia in mice. Diabetes 2013, 62(2):382-391.

54. Sullivan PM, Mezdour H, Quarfordt SH, Maeda N: Type III hyperlipoproteinemia and spontaneous atherosclerosis in mice resulting from gene replacement of mouse Apoe with human Apoe*2. J Clin Invest 1998, 102(1):130-135.

55. Arbones-Mainar JM, Johnson LA, Altenburg MK, Maeda N: Differential modulation of diet-induced obesity and adipocyte functionality by human apolipoprotein E3 and E4 in mice. Int J Obes (Lond) 2008, 32(10):1595-1605.

56. Prawitt J, Niemeier A, Kassem M, Beisiegel U, Heeren J: Characterization of lipid metabolism in insulin-sensitive adipocytes differentiated from immortalized human mesenchymal stem cells. Exp Cell Res 2008, 314(4):814-824.

57. Lefterova MI, Lazar MA: New developments in adipogenesis. Trends Endocrinol Metab 2009, 20(3):107-114.

58. Yue L, Rasouli N, Ranganathan G, Kern PA, Mazzone T: Divergent effects of peroxisome proliferator-activated receptor gamma agonists and tumor necrosis factor alpha on adipocyte ApoE expression. J Biol Chem 2004, 279(46):47626-47632.

59. Ost A, Ortegren U, Gustavsson J, Nystrom FH, Stralfors P: Triacylglycerol is synthesized in a specific subclass of caveolae in primary adipocytes. J Biol Chem 2005, 280(1):5-8.

60. Fan JY, Carpentier JL, van Obberghen E, Grunfeld C, Gorden P, Orci L: Morphological changes of the $3 \mathrm{~T} 3-\mathrm{L} 1$ fibroblast plasma membrane upon differentiation to the adipocyte form. J Cell Sci 1983, 61:219-230

61. Rothberg KG, Heuser JE, Donzell WC, Ying YS, Glenney JR, Anderson RG: Caveolin, a protein component of caveolae membrane coats. Cell 1992, 68(4):673-682

62. Razani B, Combs TP, Wang XB, Frank PG, Park DS, Russell RG, Li M, Tang B, Jelicks LA, Scherer PE, Lisanti MP: Caveolin-1-deficient mice are lean, resistant to diet-induced obesity, and show hypertriglyceridemia with adipocyte abnormalities. J Biol Chem 2002, 277(10):8635-8647.

63. Yue L, Mazzone T: Endogenous adipocyte apolipoprotein E is colocalized with caveolin at the adipocyte plasma membrane. J Lipid Res 2011, 52(3):489-498.

64. Tao H, Aakula S, Abumrad NN, Hajri T: Peroxisome proliferator-activated receptor-gamma regulates the expression and function of very-lowdensity lipoprotein receptor. Am J Physiol Endocrinol Metab 2010, 298(1):E68-E79.

65. Ko KW, Avramoglu RK, McLeod RS, Vukmirica J, Yao Z: The insulin-stimulated cell surface presentation of low density lipoprotein receptor-related protein in $3 \mathrm{~T} 3-\mathrm{L} 1$ adipocytes is sensitive to phosphatidylinositide 3-kinase inhibition. Biochemistry 2001, 40(3):752-759.

66. Ishibashi S, Perrey S, Chen Z, Osuga J, Shimada M, Ohashi K, Harada K, Yazaki Y, Yamada N: Role of the low density lipoprotein (LDL) receptor pathway in the metabolism of chylomicron remnants. A quantitative study in knockout mice lacking the LDL receptor, apolipoprotein $E$, or both. J Biol Chem 1996, 271(37):22422-22427.

67. MacArthur JM, Bishop JR, Stanford Kl, Wang L, Bensadoun A, Witztum JL, Esko JD: Liver heparan sulfate proteoglycans mediate clearance of triglyceride-rich lipoproteins independently of LDL receptor family members. J Clin Invest 2007, 117(1):153-164.

68. Wilsie LC, Chanchani S, Navaratna D, Orlando RA: Cell surface heparan sulfate proteoglycans contribute to intracellular lipid accumulation in adipocytes. Lipids Health Dis 2005, 4:2.

69. Ji ZS, Pitas RE, Mahley RW: Differential cellular accumulation/retention of apolipoprotein $E$ mediated by cell surface heparan sulfate proteoglycans. Apolipoproteins E3 and E2 greater than e4. J Biol Chem 1998, 273(22):13452-13460.

70. Nabeno-Kaeriyama Y, Fukuchi Y, Hayashi S, Kimura T, Tanaka A, Naito M: Delayed postprandial metabolism of triglyceride-rich lipoproteins in obese young men compared to lean young men. Clin Chim Acta 2010, 411(21-22):1694-1699. 
71. Choi YJ, Jo YE, Kim YK, Ahn SM, Jung SH, Kim HJ, Chung YS, Lee KW, Kim DJ: High plasma concentration of remnant lipoprotein cholesterol in obese children and adolescents. Diabetes Care 2006, 29(10):2305-2310.

72. Ma MF, Zhang Q, Liu L: Remnant lipoprotein induces adipogenic differentiation of rat adipose tissue-derived mesenchymal stem cells. Journal of Clinical Rehabilitative Tissue Engineering Research. Zhongguo Zuzhi Gongcheng Yanjiu yu Linchuang Kangfu 2010, 14(32):5992-5996.

73. Ma MF, Wen T, Liu L: Remnant-like particles activate peroxisome proliferator-activated receptor gamma and induce adipogenic differentiation of human adipose mesenchymal stem cells. Zhongguo Zuzhi Gongcheng Yanjiu yu Linchuang Kangfu 2011, 15(32):5945-5950.

74. Sattar N, Petrie JR, Jaap AJ: The atherogenic lipoprotein phenotype and vascular endothelial dysfunction. Atherosclerosis 1998, 138(2):229-235.

75. Goldberg IJ, Bornfeldt KE: Lipids and the endothelium: bidirectional interactions. Curr Atheroscler Rep 2013, 15(11):365.

76. Jagla A, Schrezenmeir J: Postprandial triglycerides and endothelial function. Exp Clin Endocrinol Diabetes 2001, 109(4):S533-S547.

77. Meyrelles SS, Peotta VA, Pereira TM, Vasquez EC: Endothelial dysfunction in the apolipoprotein E-deficient mouse: insights into the influence of diet, gender and aging. Lipids Health Dis 2011, 10:211.

78. Rutledge JC, Woo MM, Rezai AA, Curtiss LK, Goldberg IJ: Lipoprotein lipase increases lipoprotein binding to the artery wall and increases endothelial layer permeability by formation of lipolysis products. Circ Res 1997, 80(6):819-828.

79. Tang W, Zeve D, Suh JM, Bosnakovski D, Kyba M, Hammer RE, Tallquist MD, Graff JM: White fat progenitor cells reside in the adipose vasculature. Science 2008, 322(5901):583-586.

doi:10.1186/1476-511X-13-136

Cite this article as: Li and Liu: Apolipoprotein E synthesized by adipocyte and apolipoprotein E carried on lipoproteins modulate adipocyte triglyceride content. Lipids in Health and Disease 2014 13:136.

\section{Submit your next manuscript to BioMed Central and take full advantage of:}

- Convenient online submission

- Thorough peer review

- No space constraints or color figure charges

- Immediate publication on acceptance

- Inclusion in PubMed, CAS, Scopus and Google Scholar

- Research which is freely available for redistribution 